\title{
EFIKASI DIRI IBU TERHADAP EFEKTIFITAS MENYUSUI IBU POST PARTUM
}

\author{
Asrianti Safitri Muchtar ${ }^{1}$, A. Ulfa Fatmasanti ${ }^{2}$, Musni $^{3}$, Ita Novianti ${ }^{4}$ \\ 1,2,3,4Akademi Kebidanan Batari Toja Watampone \\ ${ }^{1}$ email: anthy.muchtar@gmail.com \\ email: andiulfafatmasanti@gmail.com \\ 3email:y_musni@yahoo.co.id \\ ${ }^{4}$ email: ita.novianti91@gmail.com
}

\section{ABSTRACT MOM'S SELF EFFICIENCY TOWARDS THE EFFECTIVENESS OF POST PARTUM BREASTFEEDING}

Background: Breastfeeding self-efficacy is the mother's confidence in perceiving breastfeeding ability. Breastfeeding self-efficacy will determine individual responses in the form of choices for breastfeeding behavior, efforts and abilities to face breastfeeding challenges, patterns of thought and actions, mother's emotional reactions. These consequences determine the performance of breastfeeding initiation, and the duration of breastfeeding.

Purpose: to determine the effect of mother's self-efficacy on the effectiveness of breastfeeding in the Bajoe Community Health Center, Bone Regency in 2020.

Method: This study used a cross sectional study approach. The data obtained from the results of this study are quantitative data. The sample in this study were all postpartum mothers from June to September in the Bajoe Community Health Center with a total sample size of 46 people. The sampling technique used total sampling. The data analysis used was univariate and bivariate analysis presented in the frequency distribution table. For statistical tests, the level of significance used was $p<0.05$. The analysis used to determine the effect of self-efficacy of breastfeeding mothers on the effectiveness of breastfeeding was by using the chi square test and presented in the form of a frequency distribution table.

Results: Based on the results of statistical tests using chi square, it was found that there was an effect of mother's self-efficacy on the effectiveness of breastfeeding with a value of $p=0.000$, namely $p$ value $<0.005$ so that there was an effect of mother's self-efficacy on the effectiveness of breastfeeding in the Bajoe Community Health Center, Bone Regency.

Conclusion: There is a significant influence between mother's self-efficacy on breastfeeding effectiveness in the Bajoe Community Health Center, Bone Regency.

Suggestion: It is hoped that mothers will increasa their breastfeeding self-efficacy by always increasing their knowledge about breast milk and breastfeeding so that they are able to breastfeed their babies effectively. For research sites, it is hoped that health education about breast milk and breastfeeding since the prenatal period can be routinely increased so as to increase the self-efficacy of mothers in the process of breastfeeding their babies.

Keywords: Breastfeeding, Efficacy, Effective

\section{ABSTRAK}

Latar Belakang: Breastfeeding self-eficacy adalah kepercayaan diri ibu dalam mempersepsikan kemampuan menyusui. Breastfeeding self efficacy akan menentukan respon individu berupa pilihan atas perilaku menyusui, upaya dan kesanggupan menghadapi tantangan menyusui, pola pemikiran dan tindakan, reaksi emosional ibu. Konsekuensi ini menentukan performa inisiasi menyusui, dan durasi menyusui.

Tujuan: untuk mengetahui pengaruh efikasi diri ibu terhadap efektifitas menyusui di wilayah kerja Puskesmas Bajoe Kabupaten Bone tahun 2020.

Metode penelitian: Penelitian ini menggunakan pendekatan cross sectional study. Data yang diperoleh dari hasil penelitian ini berupa data kuantitatif. Sampel dalam penelitian ini adalah semua ibu postpartum pada bulan Juni - September di wilayah kerja puskesmas Bajoe dengan jumlah sampel sebesar 46 orang. Teknik pengambilan sampel menggunakan total sampling. Analisis data yang digunakan adalah analisis univariat dan bivariat disajikan dalam tabel distribusi frekuensi. Untuk uji statistik, tingkat kemaknaan yang digunakan $p<0,05$. Analisis yang digunakan untuk mengetahui pengaruh efikasi diri ibu menyusui terhadap efektifitas menyusui adalahdengan uji chi squareserta disajikan dalam bentuk tabel distribusi frekuensi. 
Hasil: Berdasarkan hasil uji statistic menggunakan chi square didapatkan ada pengaruh efikasi diri ibu terhadapa efektifitas menyususi dengan nilai $p=0,000$ yaitu $p$ value $<0,005$ sehingga ada pengaruh efikasi diri ibu terhadap efektifitas menyusui di wilayah kerja Puskesmas Bajoe Kabupaten Bone.

Kesimpulan: Terdapat pengaruh yang signifikan antara efikasi diri ibu terhadap efektifitas menyusui di wilayah kerja Puskesmas Bajoe Kabupaten Bone.

Saran: Diharapkan ibu lebih meningkatkan kepercayaan diri dalam proses pemberian ASI dengan selalu meningkatkan pengetahuan tentang ASI dan menyusui sehingga ibu mampu menyusui bayinya secara efektif. Bagi tempat penelitian diharapkan memberikan pendidikan kesehatan tentang ASI dan menyusui sejak masa prenatal secara rutin sehingga mampu meningkatkan kepercayaan diri ibu dalam proses menyusui bayinya.

Kata Kunci: Menyusui, Efikasi, Efektifitas

\section{PENDAHULUAN}

Pemberian ASI (Air Susu lbu) secara universal telah diketahui memberi manfaat yang luar biasa bagi ibu dan bayi berdasarkan berbagai bukti penelitian yang telah banyak dilakukan sejak tahun 1980 (Hoddinot, Tappin, \& Wright, 2008) Pada tahun 2003 WHO (World Health Organization) merekomendasikan pemberian ASI secara eksklusif selama enam bulan, namun sayangnya hingga abad ke-20 pemberian ASI menjadi sangat disepelekan oleh adanya pengaruh pseudoscience, dogma medis dan promosi sosial secara massive produk-produk pengganti ASI sehingga angka menyusui di negaranegara berkembang tetap rendah (Dykes, 2011)

Laporan Riskesdas 2013, menunjukkan kecenderungan proses mulai menyusu pada anak umur 0-23 bulan dinilai bahwa proses menyusu kurang dari satu jam meningkat menjadi 34,5\% (2013) dari 29,3\% (2010). Namun, kecenderungan pola menyusui tersebut akan semakin menurun seiring meningkatnya umur bayi dengan persentasi terendah pada bayi umur 6 bulan $(30,2 \%)$ dari persentasi $52,7 \%$ pada bayi umur 0 bulan. (Riskesdas, 2013)

Pada dasarnya pemberian ASI eksklusif akan berhasil apabila didukung oleh berbagai kebijakan seperti cuti untuk ibu menyusui, penyediaan fasilitas menyusui di tempat kerja, monitoring dan evaluasi kebijakan, penetapan sanksi untuk tenaga kesehatan yang memberikan dan mengedarkan susu formula, dan peningkatan kualitas ante-natal care.

Provinsi Sulawesi Selatan Jumlah bayi yang diberi ASI eksklusif di Sulawesi Selatan pada tahun 2013 mencapai 69,3\%. Sedangkan di Kabupaten Bone sebesar $57.48 \%$. Jumlah bayi di kabupaten Bone sebanyak 8.330 bayi, dan yang di beri ASI eksklusif hanya sekitar 4.788 bayi dari jumlah tersebut, yang berarti belum mencapai standar minimum jika dibandingkan dengan target $80 \%$ yang ditetapkan Kementerian Kesehatan. (DinkesSulsel, 2014)
Menurut Dennis and Faux Breastfeeding selfeficacy adalah kepercayaan diri ibu dalam mempersepsikan kemampuan menyusui yang diukur dengan breastfeeding self-efficacy scale (BSES). Breastfeeding self efficacy akan menentukan respon individu berupa pilihan atas perilaku menyusui, upaya dan kesanggupan menghadapi tantangan menyusui, pola pemikiran dan tindakan, reaksi emosional ibu. Konsekuensi ini menentukan performa inisiasi menyusui, dan durasi menyusui (Otsuka, Taguri, Dennis, Wakutani, Yamaguchi, \& Jimba, 2014). Faktor yang dapat mendukung tindakan menyusui efektif antara lain keyakinan diri bahwa mampu untuk menyusui secara efektif.

Keberhasilan dalam memberikan ASI secara eksklusif harus didukung dengan tindakan menyusui yang efektif. Keefektifan proses menyusui didefinisikan sebagai proses interaktif antara ibu dan bayi yang berakibat secara langsung pada transfer ASI dari payudara ibu kepada bayi, dalam perilaku yang menggambarkan terpenuhinya kebutuhan ibu dan bayi (Mulder, 2006).

Berbagai alasan yang dikemukakan ibu berhenti menyusui diantaranya adalah produksi ASI dikhawatirkan kurang, puting lecet, terbenam atau terlalu besar, bayi menolak menyusu, payudara bengkak, bayi menolak payudara ibu, terlalu cepat memperkenalkan dot, bayi dianggap kurang puas dengan ASI, bayi menangis, ibu kelelahan, berat badan bayi dinilai tidak bertambah, belum lagi karena alasan ibu harus bekerja atau meninggalkan bayi beberapa waktu lamanya, hingga masalah terhambatnya ASI keluar pada hari-hari pertama postpartum sehingga ibu tidak memberikan minuman pertama selain ASI (Kronborg, Harder, \& Hall, 2015). lbu dengan breastfeeding self efficacy yang rendah cenderung menggunakan teknik alternatif untuk menyusui bayinya saat menghadapi masalah selama menyusui (Keemer, 2011). Pada akhirnya kendalakendala yang dialami ibu mempengaruhi kepercayaan diri dan keyakinan diri ibu dalam 
memberikan ASI (breastfeeding self efficacy) (Loke \& Chan, 2013).

Berbagai penelitian menunjukkan bahwa breastfeeding self efficacy merupakan faktor penting yang berhubungan dengan inisiasi, durasi, dan asi eksklusif (McQueen, Dennis, Stremler, \& Norman, 2011). Breastfeeding self efficacy yang tinggi cenderung mempengaruhi ibu untuk tetap menyusui bayinya selama 4 bulan pertama postpartum (Blyth, Creedy, Dennis, Moyle, Pratt, \& DeVries, 2002). Penelitian yang dilakukan Gercek, dkk menemukan bahwa terdapat hubungan antara rata-rata skor breastfeeding self efficacy ibu post partum dengan rata-rata skor LATCH. Dimana peningkatan breastfeeding self efficacy dapat meningkatkan kapabilitas ibu dalam menyusui efektif (Gercek, Karabudak, Celik, \& Saruhan, 2017). Penelitian lain menyebutkan bahwa terdapat hubungan antara breastfeeding self-efficacy dengan keberhasilan pemberian ASI ekslusif pada ibu post partum (Rahayu, 2018)

\section{METODE PENELITIAN}

Desain penelitian ini menggunakan pendekatan cross sectional. Data yang diperoleh dari hasil penelitian ini berupa data kuantitatif. (Notoadmodjo, 2012)

Sampel dalam penelitian ini adalah semua ibu postpartum pada bulan Juni - Septemberdi wilayah kerja puskesmas Bajoe dengan jumlah sampel sebesar 46 orang.teknik pengambilan sampel menggunakan total sampling.

Intrumen pengumpulan data pada penelitian ini adalah pengukuran derajat kepercayaan diri ibu menyusui menggunakan skala efikasi diri menyusui versi revisi (Breastfeeding Self Efficacy Scale - Short Form) yang telah ditranslasi ke dalam bahasa Indonesia. Instrumen ini berisi 14 item pernyataan tentang ekspektasi dan pemikiran ibu tentang menyusui dan tindakan menyusui dikaitkan dengan derajat kepercayaan diri. Skala pengukuran terdiri dari 5 derajat kepercayaan diri (likert) dengan range skor minimum 14 dan maksimum 70 (Dennis, 2003). Untuk mengukur efektivitas menyusui, menggunakan instrumen penilaian menyusui oleh Unicef Breastfeeding Observation Aid terdiri dari 30 item penilaian umum, keadaan payudara ibu, posisi bayi, perlekatan bayi, dan kondisi hisapan bayi sebagai indikator penting proses menyusui berjalan dengan baik dan berkualitas.

Analisis data yang digunakan adalah analisis univariat dan bivariat disajikan dalam tabel distribusi frekuensi. Untuk uji statistik, tingkat kemaknaan yang digunakan $p<0,05$. Analisis yang digunakan untuk mengetahui pengaruh efikasi diri ibu menyusui terhadap efektifitas menyusui adalah uji chi square (Dahlan, 2014).

\section{HASIL PENELITIAN \\ Deskripsi karakteristik responden \\ Tabel 1. \\ Distribusi Frekuensi Karakteristik Responden di Wilayah Kerja Puskesmas Bajoe}

\begin{tabular}{lcc}
\hline Karakteristik & $\begin{array}{c}\text { Frekuensi } \\
\text { (f) }\end{array}$ & $\begin{array}{c}\text { Persentase } \\
\text { (\%) }\end{array}$ \\
\hline Umur & 7 & 15,2 \\
$<20$ tahun & 32 & 69,6 \\
$20-35$ tahun & 7 & 15,2 \\
$>35$ tahun & & \\
Paritas & 7 & 15,2 \\
Primipara & 36 & 78,3 \\
Multipara & 3 & 6,5 \\
Grandemultipara & & \\
Pendidikan & 15 & 32,6 \\
SD & 10 & 21,7 \\
SMP & 13 & 28,3 \\
SMA & 8 & 17,4 \\
Perguruan tinggi & & \\
Pekerjaan & 22 & 47,8 \\
lbu rumah tangga & 22 & 52,2 \\
lbu bekerja & 24 & \\
Riwayat menyusui & & 34,8 \\
Tidak & 16 & 65,2 \\
Ya & 30 & \\
\hline
\end{tabular}

Berdasarkan data di atas menunjukkan bahwa dari 46 responden yang diteliti, terdapat responden dengan umur $<20$ tahun sebanyak 7 orang $(15,2 \%)$, responden dengan umur 20-35 tahun sebanyak 32 orang $(69,6 \%)$, dan responden dengan umur $>35$ tahun sebanyak 7 orang $(15,2 \%)$. Responden dengan paritas primipara sebanyak 7 orang $(15,2 \%)$, multipara sebanyak 36 orang $(78,3 \%)$ dan grandemultipara sebanyak 3 orang $(6,5 \%)$. Responden dengan pendidikan SD sebanyak 15 orang $(32,6 \%)$, SMP sebanyak 10 orang $(21,7 \%)$, SMA sebanyak 13 orang $(28,3 \%)$ dan Perguruan tinggi sebanyak 8 orang $(17,4 \%)$. Responden dengan pekerjaan ibu rumah tangga sebanyak 22 orang $(47,8 \%)$ dan ibu bekerja sebanyak (24 orang $(52,2 \%)$. Karakteristik responden dengan riwayat menyusui ya sebanyak 30 orang $(65,2 \%)$ dan yang tidak pernah menyusui sebanyak 16 orang $(34,8 \%)$.

Tabel 2.

Distribusi Frekuensi Efikasi Diri Ibu di Wilayah Kerja Puskesmas Bajoe 


\begin{tabular}{lcc}
\hline Efikasi Diri lbu & Frekuensi & Persentase (\%) \\
\hline Percaya diri & 33 & 71,7 \\
Tidak percaya diri & 13 & 28,3 \\
\hline
\end{tabular}

Tabel 2 diatas menunjukkan bahwa dari 46 responden yang diteliti, terdapat responden dengan kategori percaya diri sebanyak 33 orang $(71,7 \%)$ dan terdapat 13 orang $(28,3 \%)$ yang tidak percaya diri.

Tabel 3.

Distribusi Frekuensi Efektifitas Menyusui lbu di Wilayah Kerja Puskesmas Bajoe

\section{Deskripsi Pengaruh Efikasi Diri lbu terhadapEfektifitas Menyusui}

Tabel 4.

Pengaruh Efikasi Diri lbu Terhadap Efektifitas Menyusui di Wilayah Kerja Puskesmas Bajoe

\begin{tabular}{|c|c|c|c|c|c|c|}
\hline \multirow{3}{*}{ Efikasi Diri Responden } & \multicolumn{4}{|c|}{ Efektifitas Menyusui } & \multirow{3}{*}{ Total } & \multirow{3}{*}{ Nilai $p$} \\
\hline & \multicolumn{2}{|c|}{ Efektif } & \multicolumn{2}{|c|}{ Tidak efektif } & & \\
\hline & $\mathrm{n}$ & $\%$ & $\mathrm{n}$ & $\%$ & & \\
\hline Percaya Diri & 30 & 65,2 & 3 & 6,5 & $33(71,7 \%)$ & 0000 \\
\hline Tidak percaya diri & 4 & 8,7 & 9 & 19,6 & $13(28,3 \%)$ & 0,000 \\
\hline Total & 34 & 73,9 & 12 & 26,1 & $46(100 \%)$ & \\
\hline
\end{tabular}

Tabel 4. Diatas menunjukkan bahwa dari 33 responden memiliki kepercayaan diri menyusui terdapat 30 responden $(65,2 \%)$ yang menyusui bayinya secara efektif (menyusui berjalan dengan baik) dan terdapat 3 responden (6,5\%) yang memiliki hambatan dalam proses menyusui (tidak efektif). Tabel di atas juga menunjukkan bahwa dari 13 responden yang tidak percaya diri terdapat 4 responden $(8,7 \%)$ yang menyusui berjalan baik dan terdapat 9 responden $(19,6 \%)$ yang memiliki hambatan dalam proses menyusui. Dari tabel di atas diperoleh nilai $p$ value $0,000<0,05$ yang menunjukkan ada pengaruh efikasi diri terhadap efektifitas menyusui ibu postpartum di Wilayah Kerja Puskesmas Bajoe Kabupaten Bone.

\section{PEMBAHASAN}

Efikasi diri didefinisikan sebagai proses kognitif dari kepercayaan diri individu dalam mempersepsikan kemampuan untuk meregulasikan motivasi, proses pemikiran, status emosional dan lingkungan sosial dalam menampilkan perilaku spesifik (Bandura, 1999). Efikasi diri menyusui atau Breastfeeding Self Efficacy adalah keyakinan diri seorang ibu pada kemampuannya untuk menyusui atau memberikan ASI pada bayinya. Keefektifan proses menyusui oleh Mulder (2006), didefinisikan sebagai proses interaktif antara ibu dan bayi yang

\begin{tabular}{lcc}
\hline $\begin{array}{l}\text { Efektifitas } \\
\text { menyusui }\end{array}$ & Frekuensi & $\begin{array}{c}\text { Persentase } \\
(\%)\end{array}$ \\
\hline Efektif & 34 & 73,9 \\
Tidak Efektif & 12 & 26,1 \\
\hline
\end{tabular}

Tabel 3 di atas menunjukkan bahwa dari 46 responden yang diteliti, terdapat responden dengan kategori menyusui efektif (menyusui berjalan baik) sebanyak 34 orang $(73,9 \%)$ dan terdapat 12 orang $(26,1 \%)$ dengan kategori menyusui tidaak efektif (terdapat hambatan menyusui). berakibat secara langsung pada transfer ASI dari payudara ibu kepada bayi, dalam perilaku yang menggambarkan terpenuhinya kebutuhan ibu dan bayi. Menurutnya terdapat empat indikator dalam proses menyusui yang efektif, yaitu posisi tubuh, perlekatan yang tepat, hisapan yang efektif dan transfer ASI.

Penelitian ini menunjukkan bahwa dari 33 responden memiliki kepercayaan diri menyusui terdapat 30 responden $(65,2 \%)$ yang menyusui bayinya secara efektif (menyusui berjalan dengan baik) dan terdapat 3 responden $(6,5 \%)$ yang memiliki hambatan dalam proses menyusui (tidak efektif). Tabel di atas juga menunjukkan bahwa dari 13 responden yang tidak percaya diri terdapat 4 responden $(8,7 \%)$ yang menyusui berjalan baik dan terdapat 9 responden $(19,6 \%)$ yang memiliki hambatan dalam proses menyusui. Dari hasil uji statistic chi square didapatkan nilai $p=0,000$ dimana $p<0,05$ berarti dapat diinterpretasikan bahwa efikasi diri ibu berpengaruh terhadap efektifitas ibu dalam menyusui. Tidak adanya kepercayaan diri ibu atau rendahnya kepercayaan diri ibu dalam hal menyusui dapat menyebabkan persepsi, perilaku dan motivasi yang negatif. Adanya breastfeeding self efficacy yang baik, membuat ibu semakin keras berusaha agar dapat menyusui bayinya secara efektif, begitu pun sebaliknya. Breastfeeding self efficacy akan 
menentukan respon individu berupa pilihan atas perilaku menyusui, upaya dan kesanggupan menghadapi tantangan menyusui, pola pemikiran dan tindakan, reaksi emosional ibu. Konsekuensi ini menentukan performa inisiasi menyusui, dan durasi menyusui (Otsuka, Taguri, Dennis, Wakutani, Yamaguchi, \& Jimba, 2014).

Hasil penelitian ini sejalan dengan penelitian yang dilakukan oleh Gercek, dkk (2016) menemukan bahwa terdapat hubungan antara rata-rata score breastfeeding self efficacy ibu postpartum dengan score LATCH. Dimana peningkatan breastfeeding self efficacy dapat meningkatkan kapabilitas ibu dalam menyusui efektif yang tergambar dari meningkatnya skor LATCH tersebut (Gercek, Karabudak, Celik, \& Saruhan, 2017).

Penelitian ini juga sejalan dengan penelitian yang dilakukan Septrya tentang hubungan breastfeeding self-efficacy dengan keefektifan proses menyusui pada Ibu postpartum di Wilayah Kerja Puskesmas Nanggalo Padang dengan hasil penelitian menunjukkan bahwa terdapat hubungan breastfeeding self efficacy dengan keefektifan proses menyusui pada ibu post partum dengan nilai $p=0,000$ (Septrya, 2017)

Penelitian ini tidak sejalan dengan penelitian yang dilakukan oleh Pradanie di Rumkital Dr.Ramelan Surabaya dengan hasil penelitian menggunakan analisis uji korelasi Spearman rho menunjukkan bahwa nilai $p=0,976 \quad(<0,05)$ sehingga dinterpretasikan tidak ada hubungan antara breastfeeding self efficacy dengan tindakan menyusui yang efektif (Pradanie, 2015).

\section{KESIMPULAN}

Terdapat pengaruh yang signifikan efikasi diri ibu terhadap efektifitas menyusui di Wilayah Kerja Puskesmas Bajoe Kabupaten Bone.

\section{SARAN}

Diharapkan ibu lebih meningkatkan kepercayaan diri dalam proses pemberian ASI dengan selalu meningkatkan pengetahuan tentang ASI dan menyusui sehingga ibu mampu menyusui bayinya secara efektif. Bagi tempat penelitian diharapkan memberikan pendidikan kesehatan tentang ASI dan menyusui sejak masa prenatal secara rutin sehingga mampu meningkatkan kepercayaan diri ibu dalam proses menyusui bayi.

\section{DAFTAR PUSTAKA}

Bandura, A. (1999). Self-Efficacy. Encyclopedia of Human Behaviour, 71-81.
Blyth, R., Creedy, D. K., Dennis, C. L., Moyle, W., Pratt, J., \& DeVries, S. M. (2002). Effect of Maternal Confidence on Breastfeeding Duration: An Application of Breastfeeding Self-Efficacy Theory. Birth Issues in Perinatal Care Vol. 29(4), 278-284. https://doi.org/10.1046/j.1523536X.2002.00202.x

Dahlan, S. M. (2014). Statistik untuk Kedokteran dan Kesehatan. Jakarta: Epidemiologi Indonesia.

Dennis, C. L. (2003). The Breastfeeding Self-Efficacy Scale: Psychometric Assesment of the Short Form. JOGNN Vol 32(6), 734-744. https://doi.org/10.1177/0884217503258459

Dennis, C. L., \& Faux, S. (1999). Development and Psychometric Testing of The Breastfeeding Self-Efficacy Scale. Research in Nursing and Health, 399. https://doi.org/10.1002/(SICl)1098240X(199910)22:5\%3C399::AIDNUR6\%3E3.0.CO;2-4

DinkesSulsel. (2014). Profil Dinas Kesehatan Provinsi Sulawesi Selatan. Makassar: Dinas Kesehatan Provinsi Sulsel.

Dykes, F. (2011). Twenty-five Years of Breasfeeding Research in Midwifery. Midwifery, 8-14. https://doi.org/10.1016/j.midw.2010.12.003

Gercek, E., Karabudak, S., Celik, N. A., \& Saruhan, A. (2017). The Relationship Bettwen Breastfeeding Self Efficacy and Latch Score an Affecting Factors. Journal of Clinical Nursing, Vol. 26 (7-8), 994-1004. https://doi.org/10.1111/jocn.13423

Hoddinot, P., Tappin, D., \& Wright, C. (2008). Beastfeeding. BMJ, 881-887.

Keemer, F. (2011). Breastfeeding self-efficacy and alternative techniques to overcome maternal or infant breastfeeding challenges : a retrospective descriptive study. Masters by Research thesis, Queensland University of Technology.

Kronborg, H., Harder, I., \& Hall, E. O. (2015). First Time Mothers Experiences of Breastfeeding Their Newborn. Sexual and Reproductive Healthcare Vol. 6 (2), 82-87. https://doi.org/10.1016/j.srhc.2014.08.004

Loke, A. Y., \& Chan, L. S. (2013). Maternal Breastfeeding Self-Efficacy and the Breastfeeding Behaviours of Newborn in the Practice of Exlusive Breastfeeding. JOGNN, 42, 672-684. https://doi.org/10.1111/15526909.12250

McQueen, K. A., Dennis, C. L., Stremler, R., \& Norman, C. D. (2011). A Pilot Randomized Controlled Trial of a Breastfeeding Sel 
Efficacy Intervention with Primiparous Mothers. JOGNN Vol. 40, 35-46. https://doi.org/10.1111/j.15526909.2010.01210.x

Mulder, P. J. (2006). A Concept Analysis of Effective Breastfeeding. JOGNN Vol. 35 (3), 332-339. https://doi.org/10.1111/j.15526909.2006.00050.x

Notoadmodjo, S. (2012). Metode Penelitian Kesehatan. Jakarta: Rineka Cipta.

Otsuka, K., Taguri, M., Dennis, C. L., Wakutani, K., Yamaguchi, T., \& Jimba, M. (2014). Effectivenness of a Breastfeeding selfefficacy Intervention: Do Hospital Practice Make a Difference. Maternal and Child Health Journal (18), 296-306.

Pradanie, R. (2015). Paket Dukungan terhadap Breastfeeding Self-Efficacy dan Keberhasilan
Menyusui pada Ibu Postpartum. Jurnal Ners Vol. 10 No. 1 , 20-29.

Rahayu, D. (2018). Hubungan Breastfeeding Self Efficacy dengan Keberhasilan Pemberian ASI Eksklusif. Jurnal IImu Kesehatan Vol. 7, No. 1 , https://doi.org/10.32831/jik.v7i1.191

Riskesdas. (2013). Hasil Utama Riskesdas 2013. Jakarta: Badan Penelitian dan Pengembangan Kesehatan Kementerian Kesehatan.

Septrya, W. (2017). Hubungan Self-Efficacy dengan Keefektifan Proses Menyusui pada Ibu Post Partum di Wilayah Kerja Puskesmas Nanggalo Padang. Naskah tidak dipublikasikanm, Fakultas Keperawatan, Universitas Andalas, Padang. 